\title{
HEMATOLOGIC TOXICOSIS; \\ INDUCED BY DOXORUBICIN PROTECTIVE EFFECTS OF COMBINATION OF OLEA EUROPEAE AND GINKGO BILOBA
}

1. Department of Pharmacology, Ziauddin University, Karachi, Pakistan.

2. Department of Pharmacology, Ziauddin University, Karachi, Pakistan.

3. Department of Pharmacognosy, Ziauddin University, Karachi, Pakistan.

4. Department of Pharmacology, Ziauddin University, Karachi, Pakistan.

3. House Officer, Civil Hospital, Karachi, Pakistan.

Correspondence Address: Dr. Talha Bin Fayyaz

Address: Faculty of Pharmacy,

Ziauddin University,

ST-4B, Shahrah-e-Ghalib,

Block-6, Clifton, Karachi, Pakistan. talha fayyaz@yahoo.com

Article received on: 02/12/2016

Accepted for publication: 10/03/2017

Received after proof reading: 06/05/2017
Dr. Talha Bin Fayyaz', Prof. Zahida Memon², Dr. Mirza Tasawer Baig ${ }^{3}$, Dr. Noor ul Ain, Dr. Muhammad Saddam Aziz

ABSTRACT... Objectives: To evaluate the protective effects of combination of extracts of Olea europeae and Ginkgo biloba in response to hematological toxicosis induced by DOX. Design of study: Animal experimental study. Setting: Dow University of Health Sciences. Period: 2 month. Materials \& methods: The extracts of Olea europeae and Ginkgo biloba were prepared by using standard Soxhlet apparatus and then they were mixed together in 1:1 ratio. Eighteen Male Wistar rats were incorporated in the study and divided in 3 groups: $T^{\star}$ (control group: 2 $\mathrm{ml} 0.9 \% \mathrm{NS}$ ), TP0 (DOX group: $15 \mathrm{mg} / \mathrm{kg} /$ week) and TP1 (extract of Olea europeae \& Ginkgo biloba + DOX: $200+15 \mathrm{mg} / \mathrm{kg} /$ week). All animals receive drugs by intra-peritoneal route. On $57^{\text {th }}$ day blood was withdrawn by cardiac puncture and preserved for analysis. Hematological profile includes $\mathrm{CBC}$ and Platelet count. Results: Hematological analysis reveals that the animals which receive Doxorubicin had low levels of Hemoglobin, RBCs, Leukocytes, Neutrophils, Eosinophils, Monocytes, Lymphocytes and Platelets when compared to control group. The levels of $\mathrm{Hb}$ and RBCs were low but it is not evident of anemia. Neutrophil and Platelet were drastically low, which shows presence of Neutropenia and Thrombocytopenia. The treated group animals had shown positive elevation in the levels of CBC and Platelet count. Conclusions: On the basis of hematological report it is concluded that combination of extracts of Olea europeae and Ginkgo biloba can prevent the toxicosis effects of Doxorubicin.

Key words: Doxorubicin Ginkgo biloba Hematological profile Olea europeae Toxicosis

Article Citation: Fayyaz TB, Memon Z, Baig MT, Noor ul Ain, Aziz MS. Hematologic toxicosis; induced by doxorubicin protective effects of combination of olea europeae and ginkgo biloba. Professional Med J 2017;24(5):751-756.

DOI: 10.17957/TPMJ/17.3755

\section{INTRODUCTION}

In 1950's Anthracycline (first agent DAUNORUBICIN) from Streptomyces peucetius (soil bacterium) was derived. ${ }^{1}$ Later on derivative of Daunorubicin was identified i.e. Doxorubicin, which was more effective anti-tumor agent. ${ }^{2}$ DOX was a potent and highly effective drug in treating many varieties of cancer. Due to its toxic effects on heart, its usage was controlled. ${ }^{3}$ The potential mechanisms of cardiac toxicity were free radical production, lipid peroxidation ${ }^{3}$, destruction of mitochondrial assembly ${ }^{4}$, release of vasoactive amine $^{5}$ and cellular toxicity. It also reacts with iron to initiate the production of ROS which causes cell death by apoptosis. ${ }^{5}$

Olive (Olea europeae) belongs to Oleaceae family had a long history for its medicinal, nutritional and health benefit effects. Phenolic constituents including oleuropein, hydroxytyrosol and tyrosol were responsible for most of the olive pharmacologic activities. ${ }^{6}$ The extract in a time and dose dependent manner have decreased proliferation and possess cytotoxic effects, ${ }^{7}$ also inhibits production of ROS, decrease in the production of Thromboxane A2, anti-inflammatory and inhibition of platelet aggregation, ${ }^{8}$ reduces infarct size, ${ }^{9}$ produces antioxidant effect. ${ }^{6}$ The extract of Olea europeae put forth a defensive process by reducing the DOX cardiotoxicity which was articulated by the changes in peripheral and intracellular markers. It also diminished DOX provoked iNOS induction, protein carbonyls content, lipid peroxidation and nitrotyrosine concentration in myocardial tissue in a dose dependent manner. ${ }^{9}$

Ginkgo biloba tree, member of Ginkgoaceae family was recognized about 170 million years ago. ${ }^{10}$ The constituents which were present in 
Ginkgo biloba leaves were flavonol glycosides, phenolic acids, terpene trilactones, polyprenols, biflavones, alkylphenols, and proanthocyanidins. ${ }^{11}$ In all of these the two major groups were flavones glycosides having $24 \%$ fraction and the other group is terpene trilactones having $6 \%$ fraction producing positive biological effects credited to Ginkgo biloba. ${ }^{11}$ Mechanism of actions include: decreasing the release of $\mathrm{NO}$, modulation of receptor densities and concentration of neurotransmitters ${ }^{12}$, antagonism of PAF, free radical scavenging, anti-oxidant activities ${ }^{13}$ and inhibition of mitochondrial dysfunction. The extract decreases the aggregation of thrombocytes by enhancing synthesis of prostacyclins; also decreases proliferation of vascular smooth cells, enhances vessel function and prevents restenosis after angioplasty. ${ }^{14}$ Also enhances the fluidity of RBCs, improves blood flow and also reduces viscosity of entire blood. ${ }^{15}$ The current study was performed to assess the outcome of combination of extracts on hematologic toxicosis associated with Doxorubicin when administered to rats.

\section{METHODS \& MATERIALS}

The study was designed in the Department of Pharmacology, Ziauddin University and conducted in DUHS following ethical and institutional approval. The research adhered to the "Principles of Laboratory Animal Care" (NIH publication \#85-23, revised in 2011) and permitted by Board of Advance Studies and Research, Ziauddin University.

Healthy male albino Wistar rats (weight 220250gms) were purchased from AKUHS. The temperature was maintained at $23 \pm 2 \circ \mathrm{C}$. Relative Humidity was kept $65-75 \%$. Light and dark cycle of 10:14 hrs. Standard polypropylene cages with wire mesh tops were used to keep the animals. Food and tap water was provided adlibitum. The animals were adapted to the constant environment for a period of seven days with sufficient rat chow, before the dosing started.

Freshly collected leaves of Olea europeae and Ginkgo biloba in a quantity of five hundred grams each were washed and air dried. Then by using standard grinding machine the leaves were grinded to fine powder. Before extraction process, the powder was macerated for 48 hours in $90 \%$ Ethanol. After maceration the extraction was performed for two times. During each extraction approximately 1 liter of Ethanol was used. Extraction was performed by using standard soxhlet apparatus. Then by utilizing standard rotary evaporator the final filtrate was concentrated to dryness under reduced pressure. Both extracts were then mixed in a ratio of $1: 1$ at the time of administration. DMSO (Dimethyl sulfoxide) and water for injection were used as a vehicle in administration of extract by IP route. Water for injection was also used as a vehicle in administration of Doxorubicin by IP route.

Eighteen animals were incorporated in the study. Male albino whistar rats were separated further in three groups (six in each group). First group was control group labeled as $\mathrm{T}^{*}$ [received $2 \mathrm{ml}(0.9 \%)$ NS], second group was Standard group labeled as TPO [received Doxorubicin $15 \mathrm{mg} / \mathrm{kg} /$ week] and treated group was labeled as TP1 [prophylactically received extract of Olea europeae \& Ginkgo biloba $200 \mathrm{mg} / \mathrm{kg} /$ day followed by DXR $15 \mathrm{mg} / \mathrm{kg} /$ week]. The drugs were administered IP (intraperitoneal). The injections were carefully made at the midway of the xyphoid and the pelvic bone (lower right quadrant of the abdomen, close to the midline). Needle (25 needle gauge) was used to administer the doses. The doses were administered on days $1,2,3,4,5,6,7 \times 8$ weeks. The blood was sampled by cardiac puncture on day $57^{\text {th }}$ during which the animal was kept deeply anesthetized by using chloroform.

Blood drawn by cardiac puncture was collected in anticoagulant tubes. For estimation of hematological parameters, blood $(2 \mathrm{ml})$ will be collected in EDTA K3 tubes for examination of Red Blood Cells, Hemoglobin, Leucocytes, Platelets, Neutrophils, Lymphocytes, Eosinophils, Monocytes ${ }^{16}$ on automatic Humacount plus (3 part differential with histogram). Automated Hematology analyzer Model \# 16400/S, (Human Germany).

\section{STATISTICAL ANALYSIS}

Data was analyzed on SPSS version 19 with paired sample test, $p$ value $<0.05$ was considered 
significant, $p$ value $<0.01$ highly significant and $p$ value $<0.001$ was considered very highly significant.

\section{RESULTS}

Results demonstrated variation in the levels of CBC and platelet count of rats in treated group TP1 (extract of Olea europeae and Ginkgo biloba) compared with the Standard group TPO (Doxorubicin). Table-I and Figure-1 shows Hemoglobin levels were highly significantly enhanced ( $p$-value < 0.01) compared with the standard. Whereas levels of Red blood cells count were also highly significantly increased ( $p$-value $<0.01$ ) compared with the standard as shown in Figure-2. When compared with the standard levels of Leucocyte and Neutrophil count were very highly significantly enhanced ( $p$-value < 0.001 ) as shown in Figure-3, level of Lymphocytes were very highly drastically increased ( $p$-value $<0.001$ ) as shown in Figure-5 and levels of Eosinophil and Monocyte were not considerably increased ( $p$-value $>0.05$ ) as shown in Figure-6. Levels of Platelets were very highly extensively improved ( $p$-value < 0.001) as shown in Figure-4.

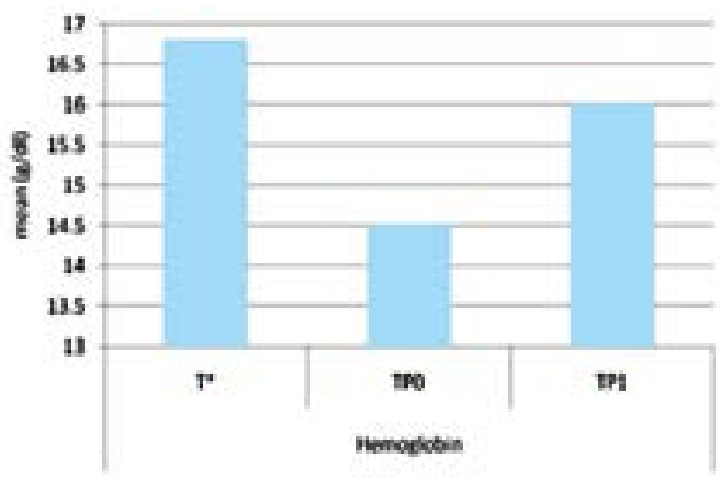

Figure-I. Hemoglobin levels of different groups

\begin{tabular}{|c|c|c|c|c|}
\hline Hematologic Profile & Groups & t-value & Degree of freedom & p-value \\
\hline Hemoglobin (g/dl) & TP0 - TP1 & 6.6058 & 5 & $0.0012^{\star \star}$ \\
\hline $\operatorname{RBC}\left(\times 10^{6} / \mathrm{mm}^{3}\right)$ & TP0 - TP1 & 4.3916 & 5 & $0.0071^{* \star}$ \\
\hline Leucocytes $\left(\times 10^{3} / \mathrm{mm}^{3}\right)$ & TP0 - TP1 & 29.1471 & 5 & $0.000^{* \star *}$ \\
\hline Platelets $\left(\times 10^{3} / \mathrm{mL}\right)$ & TP0 - TP1 & -20.9969 & 5 & $0.000 * \star \star$ \\
\hline Neutrophils $\left(\times 10^{3} / \mathrm{mm}^{3}\right)$ & TP0 - TP1 & 17.9799 & 5 & $0.000^{* \star *}$ \\
\hline Lymphocytes $\left(\times 10^{3} / \mathrm{mm}^{3}\right)$ & TP0 - TP1 & -9.5507 & 5 & $0.0002^{* \star *}$ \\
\hline Eosinophils $\left(\times 10^{3} / \mathrm{mm}^{3}\right)$ & TP0 - TP1 & -0.6670 & 5 & $0.5343^{\star \star \star *}$ \\
\hline Monocytes $\left(\times 10^{3} / \mathrm{mm}^{3}\right)$ & TP0 - TP1 & -2.0585 & 5 & $0.0946^{\star * * *}$ \\
\hline
\end{tabular}

Professional Med J 2017;24(5):751-756.

www.theprofesional.com 


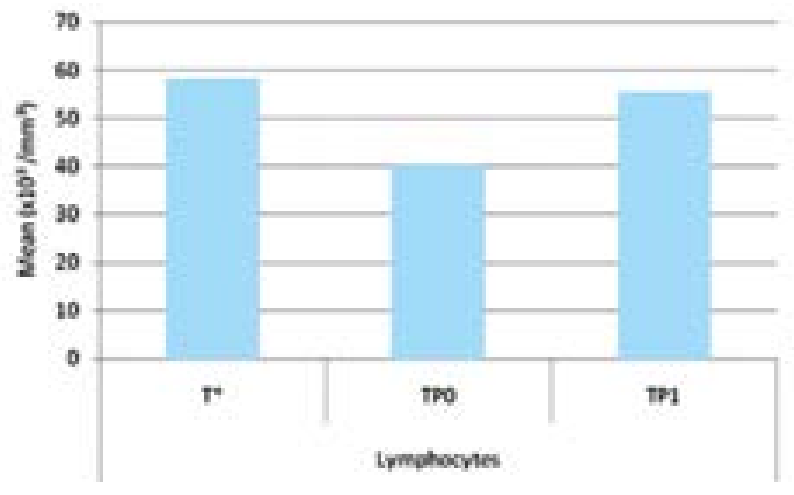

Figure-5. Lymphocyte levels of different groups

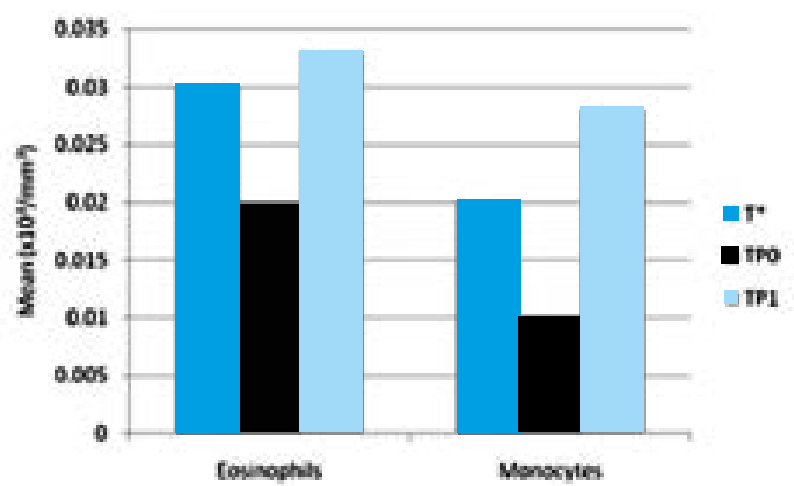

Figure-6. Comparative levels of Hematological profile of different groups

\section{DISCUSSION}

Hematological toxicity was assessed by onset and severity of anemia, thrombocytopenia, leukocytopenia, neutropenia and lymphopenia. The administration of Doxorubicin had been linked with dose related decrease in the levels of hematologic parameters. ${ }^{17}$ The levels of Hemoglobin and RBCs in standard group were considerably decreased as compared to the control group. This decrease in number of cells can be linked with the possibility of anemia in the animal due to the destruction of RBCs. Arancia $G$, et al stated in their study that Doxorubicin can cause non-regenerative anemia by causing toxic effects on erythrocyte precursors in the bone marrow or may cause regenerative anemia which is associated with increased destruction of poikilocyte. ${ }^{17}$ The proper mechanism by which DOX alters RBCs morphology is not known. Gonsalvez M, et al suggested that the potential mechanisms for poikilocytosis generation consist of development of reactive oxygen species which causes lipid peroxidation of $\mathrm{Na}+/ \mathrm{K}+$ dependent ATP activity. ${ }^{18}$ The administration of combination of extract eradicates the possibility of anemia by significantly increasing the levels of Hemoglobin and $\mathrm{RBCs}$ in the rats of treated group.

Mild Leukocytopenia was also observed in the rats receiving DOX. This results due to the immunosuppressive potential of Doxorubicin. The levels of Leukocyte were elevated after the administration of combination of extracts as shown in Figure-3. The group received Doxorubicin (standard group) shows the Neutrophil levels were drastically decrease which was an evident of Neutropenia. Neutropenia and thrombocytopenia was the most common adverse effect of Doxorubicin treatment. Drastic reductions in the levels of Thrombocytes indicate thrombocytopenia but it was not associated with any type of bleeding in the group treated with doxorubicin (standard group). The levels of Lymphocytes, Eosinophils and Monocytes were also decreased due to the administration of DOX in standard group as compared to control group. The prophylactic administration of combination of extracts (treated group) showed increase in the levels of Platelets, Neutrophils, Lymphocytes, Eosinophils and Monocytes count in a significant manner compared with the standard as shown in Figures-4,5 and 6. This indicates that the prophylactic treatment with the combination of extracts was effective in reducing Thrombocytopenia and Neutropenia associated with Doxorubicin therapy. The effects of extract imitate a rebound thrombocytosis which results in the stimulation of bone marrow due to thrombocytopenic or neutropenic episodes. ${ }^{19}$ The combination of extract may mimic the natural mechanism by which Neutropenia causes the release of Granulocyte-macrophage colonystimulating factor which in response stimulate the cell line which enhances the production of granulocytes and agranulocytes. This indicate that the combination strengthen the immune system by improving the cell count.

\section{CONCLUSION}

The study established that Prophylactic treatment 
with combination of extracts of Olea europeae and Ginkgo biloba produces characteristic preventive effects on Doxorubicin induced hematologic toxicosis in rats.

Copyright(c) 10 Mar, 2017.

\section{REFERENCES}

1. Di Marco A, Cassinelli G, Arcamone F. The discovery of daunorubicin. Cancer Treat Rep. 1981; 65(4): 3-8.

2. Arcamone F, Cassinelli G, Fantini G. Adriamycin, 14hydroxydaunomycin, a new antitumor antibiotic from S. peucetius var. caesius. Biotechnol Bioeng. 1969; 11(6): 1101-10.

3. Pfeffer B, Tziros C, Katz RJ. Current Concepts of Anthracycline Cardiotoxicity: Pathogenesis, Diagnosis and Prevention. Br J Cardiol. 2009; 16(2): 85-89.

4. Tokarska-Schlattner M, Dolder M, Gerber I, Speer $O$, Wallimann T, Schlattner U. Reduced creatinestimulated respiration in doxorubicin challenged mitochondria: particular sensitivity of the heart. Biochim Biophys Acta. 2007; 1767(11): 1276-84.

5. Kotamraju S, Kalivendi SV, Konorev E, Chitambar $\mathrm{CR}$, Joseph J, Kalyanaraman B. Oxidant-induced iron signaling in Doxorubicin-mediated apoptosis. Methods Enzymol. 2004; 378: 362-82.

6. Ghanbari R, Anwar F, Al kharfy KM, Gilani AH, Saari $\mathrm{N}$. Valuable Nutrients and Functional Bioactives in Different Parts of Olive (Olea europaea L.)-A Review. Int. J. Mol. Sci. 2012; 13: 3291-3340.

7. Allouche $Y$, Warleta F, Campos M, Sánchez-Quesada C, Uceda M, Beltrán G, Gaforio JJ. Antioxidant, antiproliferative, and pro-apoptotic capacities of pentacyclic triterpenes found in the skin of olives on MCF-7 human breast cancer cells and their effects on DNA damage. Journal of Agricultural and Food Chemistry. 2011; 59(1): 121-130.

8. Pieroni A, Heimler D, Pieters L, van Poel B, Vlietinck AJ. In vitro anti-complementary activity of flavonoids from olive (Olea europaea L.) leaves. Pharmazie. 1996; 51: 765-768.
9. Andreadou I, Sigala F, lliodromitis EK, Papaefthimiou M, Sigalas C, Aligiannis N, Savvari P, Gorgoulis V, Papalabros E, Kremastinos DT. Acute doxorubicin cardio toxicity is successfully treated with the phytochemical oleuropein through suppression of oxidative and nitrosamine stress. Journal of Molecular and Cellular Cardiology. 2007; 42: 549-558.

10. Zhou Z, Zheng S. The missing link in Ginkgo evolution. Nature. 2003; 423: 821-822.

11. Van Beek TA, Montoro P. Chemical analysis and quality control of Ginkgo biloba leaves, extracts, and phytopharmaceuticals. J. Chromatogr. A. 2009; 1216: 2002-2032.

12. Diamond BJ, Shiflett SC, Feiwel N, Matheis RJ, Noskin $O$, Richards JA, Schoenberger NE. Ginkgo biloba extract: Mechanisms and clinical indiratsions. Arch. Phys. Med. Rehabil. 2000; 81: 668-678.

13. Shi C, Liu J, Wu F, Yew DT. Ginkgo biloba extract in Alzheimer's disease: From action mechanisms to medical practice. Int. J. Mol. Sci. 2010a; 11: 107-123.

14. Lin SJ, Yang TH, Chen YH, Chen JW, Kwok CF, Shiao M. Effects of Ginkgo biloba extract on the proliferation of vascular smooth muscle cells in vitro and on intimal thickening and interleukin-1b expression after balloon injury in cholesterol-fed rabbits in vivo. J. Cell Biochem. 2002; 85: 572-582.

15. Dubey AK, Shankar PR, Upadhyaya D, Deshpande VY. Ginkgo biloba-an appraisal. Kathmandu Univ Med J (KUMJ). 2004; 2(3): 225-229.

16. Newland, A. Thrombopoietin mimetic agents in the management of immune thrombocytopenic purpura. Seminars in Hematology, 2007; 44: S35-S45.

17. Arancia G, Molinari A, Crateri P, et al. Adriamycin-plasma membrane interaction in human erythrocytes. Eur $\mathrm{J}$ Cell Biol. 1988; 47: 379-387.

18. Gonsalvez M, Van Rossum GDV, Blanco MF. Inhibition of sodium potassium activated adenosine-5triphosphatase and ion transport by Adriamycin. Cancer Res. 1979; 39: 257-261.

19. McDonald TP. Regulation of megakaryocytopoiesis by thrombopoietin. Ann NY Acad Sci. 1987; 509: I-24. 


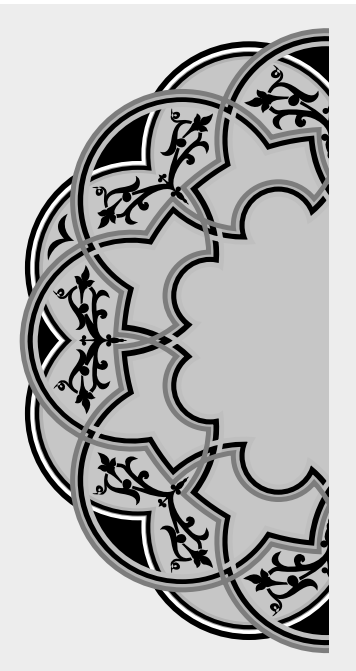

\title{
"Expect the best, Prepare for the worst."
}

\author{
Muhammad Ali Jinnah
}

\begin{tabular}{|c|c|c|}
\hline \multicolumn{3}{|c}{ AUTHORSHIP AND CONTRIBUTION DECLARATION } \\
\hline Sr. \# & Author-s Full Name & \multicolumn{1}{c|}{ Contribution to the paper } \\
\hline 1 & Dr. Talha Bin Fayyaz & $\begin{array}{l}\text { Conception and designing of work, } \\
\text { interpretation of data, drafting } \\
\text { and final approval of manuscript, } \\
\text { perform experimental work. } \\
\text { Interpretation of data and give } \\
\text { her expert view for manuscript } \\
\text { designing. Giver research opinion } \\
\text { and experience in finalizing the } \\
\text { manuscript } \\
\text { Help in procurement of herbs, } \\
\text { preparation of extracts, and } \\
\text { drafting. } \\
\text { Contributed in conception, Help in } \\
\text { experimental work, data collection } \\
\text { and manuscript writing. } \\
\text { Help in drafting and performing } \\
\text { experimental work. Procurement of } \\
\text { Drug. }\end{array}$ \\
\hline 5 & Prof. Zahida Memon \\
\hline 5 & Dr. Mirza Tasawer Bar. M. Saddam Aziz & Din
\end{tabular}

